\title{
An Ontological Model of Experience-Based Knowledge Management in Agile Software Development Environment
}

\author{
Nik Sakinah Nik Ab Aziz and Rusli Abdullah
}

\begin{abstract}
Agile software development (ASD) involves more in discussion and communication between team members compared to documentation; it is difficult for team members to share knowledge among them. In this matter, knowledge management (KM) plays critical role in managing and capturing the knowledge especially experience-based knowledge. This research main purpose is to create ontology to represent the knowledge that has been stored in knowledge repository after capturing the experience knowledge from the development team in ASD. This ontology model will help by describing a relationship that will later on help in sharing the experience knowledge easily among Community of Practice (CoP). A literature review of the common things in the ASD been conducted, we then creating ontology model by using a tools called Protégé. This ontology called as Experience-Based Knowledge Management (EBKM) Ontology Model. The model is deployed to apply to the reality as a prototype to demonstrate its real value.
\end{abstract}

Index Terms-Agile software development, knowledge management, ontology, experience-based factory, community of practice.

\section{INTRODUCTION}

Agile have a lot of methodologies that helps in various part of ASD process. Some examples of the methodologies are Extreme Programming (XP), Scrum, Dynamic Systems Development Method (DSDM), and Feature Driven Development (FDD). Each methodology has its own goal to achieve in ASD process. Since ASD involves more in discussion and communication between team members compared to documentation, it is difficult for team members to share knowledge among them. Hence, the knowledge in the development team should be captured and manage so that they can share the knowledge or information easily. In this matter, knowledge management (KM) plays big role in managing and capturing the knowledge especially experience-based knowledge. KM in software development (SD) is not a new topic, it been discuss many years back on how to manage the knowledge of development especially experience-based knowledge by creating knowledge factory. By using this kind of factory in SD, it will encourage community of practices (CoP) such as engineers and developers to share knowledge and work together in

Manuscript received March 1, 2014; revised May 8, 2014.

Nik Sakinah Nik Ab Aziz and Rusli Abdullah are with the Faculty of Computer Science and Information Technology, Universiti Putra Malaysia (UPM), 43400 UPM Serdang, Selangor Darul Ehsan, Malaysia (e-mail: sakinah112@gmail.com, rusli@upm.edu.my). developing software especially which related to agile software development (ASD) environment [1]. Ontology helps to share common understanding of the knowledge, ease changes in domain knowledge (add, delete class / instance) [2].

This research main purpose is to create ontology to represent the knowledge that been stored in knowledge repository after capturing the experience knowledge from the development team in ASD. This ontology model will help by describe a relationship that will later on help in sharing the experience knowledge easily among Community of Practice $(\mathrm{CoP})$. One of the objectives of this research is to propose an ontology model experience-based of knowledge management in ASD. A literature review of the common things in the ASD been conducted, we then creating ontology model by using a tools called protégé. In this ontology, all classes and properties are defined based on the findings. This ontology called as Experience-Based Knowledge Management (EBKM) Ontology Model. The other objective is to develop a prototype based on the ontology model proposed. The ontology was evaluated based on the usefulness in practice which are the ontology helped in saving development time and reduce development cost (such as resources, expenses, and tools) as stated by R. Abdullah et al. [1]. The model is deployed to apply to the reality as a prototype to demonstrate its real value. This research only focused on agile software development based on XP and Scrum methodology. The ontology is created to describe the connection between each practice in ASD.

\section{LITERATURE REVIEW}

\section{A. Agile Software Development}

Agile SDLC is a combination of iterative and incremental process models which focus on process adaptability and customer satisfaction by rapid delivery of working software product [3]. The author conclude that in each of the iterations, consists of planning, requirement analysis, designing, building and testing. Sheetal Sharma et al. [4], the agile process follows the software development life cycle which includes requirements gathering, analysis, design, coding, testing and deliver partially software, and feedback. In the whole process, customer satisfaction is the higher priority. There are several of agile methodologies that can be used in agile software development. Cockburn and Highsmith explain what is new about agile methods is not the practices they use, but their recognition of people as the main driving force which can lead to project success [5]. Many researchers 
claimed XP and Scrum methodologies are widely used in the industry and are the most popular (e.g. [6]-[8]). The details of $\mathrm{XP}$ and Scrum practices are given by K. Beck [9] and K. Schwaber, and J. Sutherland [10].

\section{B. Knowledge Management}

The categorization of knowledge is managed based on agile development process as what been discussed by Graeme Smith et al. [11]. In this context, the KMS will also be functionalized and allowed the community of practice $(\mathrm{CoP})$ to work together collaboratively and at the same time or different place in promoting knowledge sharing process among $\mathrm{CoP}$ for developing system application by using agile methodologies [1]. A new access control is named as Formula-Based Cloud Data Access Control (FCDAC) has been introduced to manage knowledge in cloud computing [12]. Modi Lakulu et al. [13], discuss the formulation of KMS framework for sharing knowledge in OSS using SDLC from the planning phase until the maintenance phase. The purpose of this KMS model is to allow OSS Community of Practice to share the knowledge.

\section{Knowledge Management and ASD}

KM and Agile Software Development (ASD) are two organizational processes that face common barriers when introduced and applied in software development. The main barrier in initiating the product development in agile software development and implementing $\mathrm{KM}$ into software organizations is the need to deal with the conceptual change, mainly the organizational cultural change that ASD and KM brings when introduced [14]. Many studies have revealed that the introduction of KM and ASD processes have increased productivity, shortened time-to-market and resulted in higher product quality (e.g. [15], [16]). Boehm and Turner [17] note that agile methods rely on tacit knowledge and it depends on the ability to cultivate and share it. The pairing of KM and ASD is not new; a connection between the two concepts has been recognized by various researchers [18]-[22].

\section{Ontology}

There are several ontology languages available such as Resource Description Framework (RDF) [23], Web Ontology Language (OWL) [24], DARPA Agent Markup Language (DAML) [25], Ontology Interchange Language (OIL) [26], DAML+OIL [27], Simple HTML Ontology Extensions (SHOE) [28] etc. for capturing knowledge of interest. Different ontology languages have different facilities. The most recent development in standard ontology languages is OWL from the World Wide Web Consortium (W3C) (http://www.w3.org/). It has the most complete set of expressions for capturing the different concepts and relationships that occur within ontologies; therefore, the software engineering knowledge is captured in OWL [29].

\section{E. Ontology Model in Software Development}

Relationship between ontologies and agile methods always appears in literature. Knublauch [30] believes that by using the correct tools, ontology given development can be applied more in agile development. However, there is no generic ontology have been proposed. Reflect to the previous paper,
David [31] has proposed an ontology model. The researcher use the ontology approach to analyzing the core component of an agile methodology based on an existing literature that related to agile methodology. David believes this will assist our understanding of the kernel of Software Engineering (SE) theory that underlies within agile methodology. Pornpit Wongthongtham et al. [29] has created an ontology based on UML diagram to describe each phases in software engineering cycle generally. They use class diagram, entity relationship diagram, activity diagram and some use case diagram to describe the ontology. From the model, the researchers develop a prototype to visualize the ontology. As a result, it shows the ontology shows it is useful in practice.

\section{Methodology}

In order to create a model of knowledge sharing, there are few steps that have been taken, as shown in Fig. 1 below.

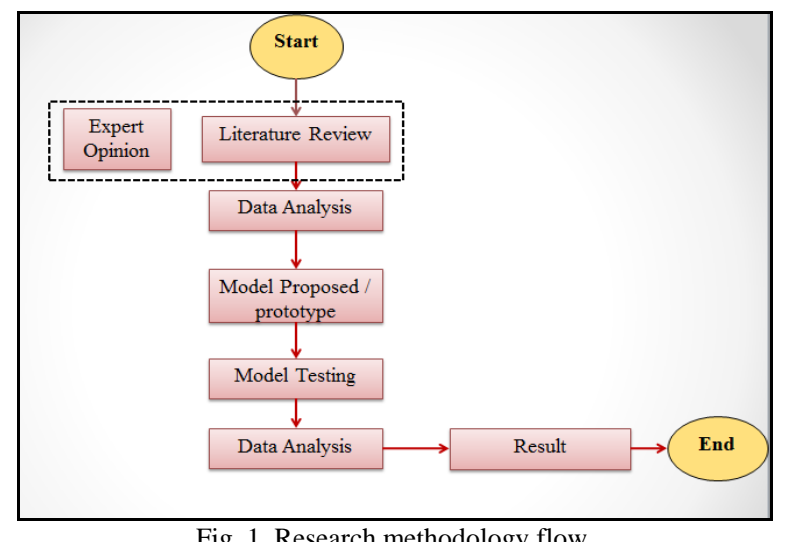

Fig. 1. Research methodology flow.

Our research is start by done some literature review to find out the common things in ASD and KM for Agile practices. By analyzing the collected data, we came out with the result. The results from the literature review then reviewed by some expert such as system engineer and developer in agile development environment who has more than 2 years of experience in ASD. We finally created the model that proposed named Experience-Based Knowledge Management (EBKM) ontology model. This model develops by using Protégé 4.

The prototype was developed in order to evaluate the model and also to help user to understand how this ontology helps in sharing the knowledge between team members. This prototype was developed by using PHP language and MySQL database with Apache service. We then run a survey to a $\mathrm{CoP}$ (scrum master, developer, project manager, and tester) that involved directly in agile software development by distributing the questionnaires.

There were about 25 respondents ( 14 man and 11 women) that involved in the survey. The respondents mostly have agile development experience around two years and above. The data analysis was done based on the collected data from this survey. The result was analyze based on the usefulness of the model either it helps in saving time and reduce cost of the software development especially in agile.

\section{A. EBKM Ontology Model}

Manjula Shenoy et al. [32] presented the scope of ontology 
mapping, how the ontology mapping processed and steps involved. It compares the features of various ontology mapping systems and the language, Strategy used in each approach and their advantages and disadvantages. By refer to the articles written by A.Rabiyathul Basariya eand O.S Jannahath Nisha [33], we create the ontology model. This paper was creating ontology model for education domain. The model then will be used as a reference to link information in the university website to get the relevant information. The steps creating the Experience-Based Knowledge Management (EBKM) ontology model are as Fig. 2 below:

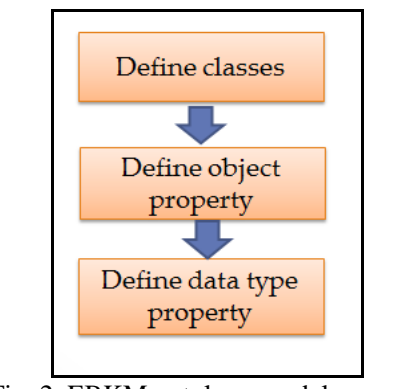

Fig. 2. EBKM ontology model process.

\section{B. Define Class}

Based on literature review and expert opinion, we have five classes which are planning, analysis, design, implementation and feedback. The subclass are user stories, onsite customer, sprint plan meeting that consist of product backlog and sprint backlog, pair programming, collaborative workspace, daily scrum meeting and collective ownership. All the classes are coming under <owl:Thing> class [33].

\section{Define Object and Datatype Property}

Properties are included both object property and datatype property. Object property relates object to other object. For example the property usePairProgramming belongs to the class Pair Programming. Data type properties, which relate objects to datatype values. Each datatype properties have the range that specifies the type of data. Property has certain domain. Domain indicates in which class the property belongs to [33]. For examples, in user stories domain it have few characteristic which are having project id which project this story belongs to, use story id, user story title so developer and customer can refer to it easily, the description what should be in the system for that user story and etc.

\section{EBKM Ontology Model}

Various formalisms have been developed for modelling ontologies, notably the Knowledge Interchange Format (KIF) [34] and knowledge representation languages descended from KL-ONE [35]. However, these representations have had little success outside Artificial Intelligence (AI) research laboratories [36], [37] and require a steep learning curve. In this study, graphical notations of modelling agile software development ontology as an alternative formalism are presented. The main aim is not only to create a graphical representation to make it easier to understand, but importantly, this model should be able to capture the semantic richness of the defined agile development ontology [36]. The ontology model of EBKM is shown in Fig. 3 below.

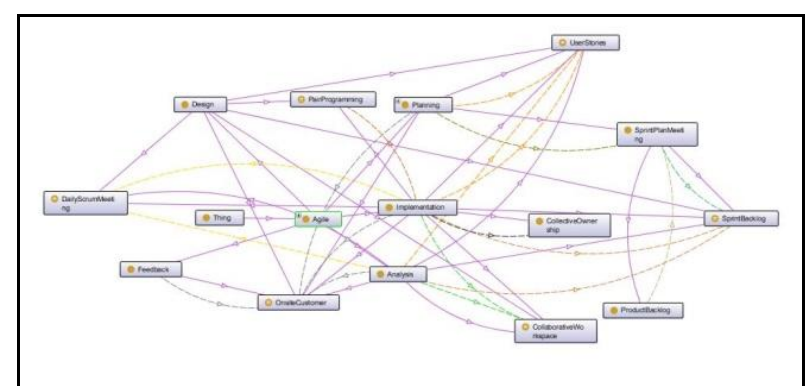

Fig. 3. EBKM ontology model in ontograf view.

\section{E. EBKM System Prototype}

This prototype only covers some part of the ontology. We choose the most important part to show to the CoP which is user stories. This prototype shows how ontology helps in sharing the development knowledge. Fig. 4-Fig. 6 below are some of the web page that shown how the knowledge is shared. The evaluation of EBKM ontology model is through the deployment ontology on the platform.

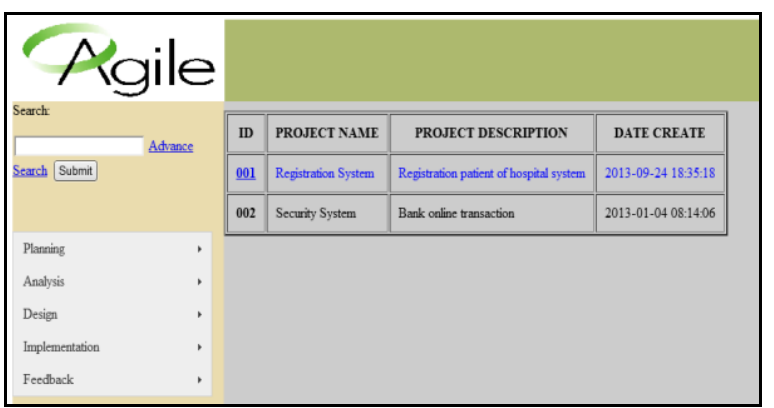

Fig. 4. EBKM system (main menu).

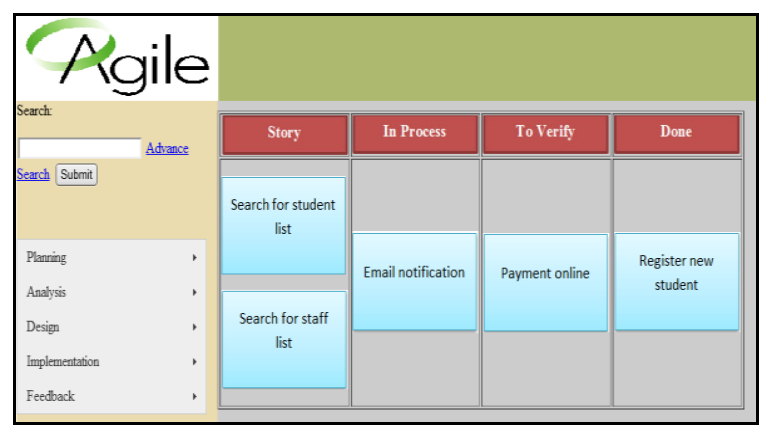

Fig. 5. EBKM system (e-collaborative workspace)

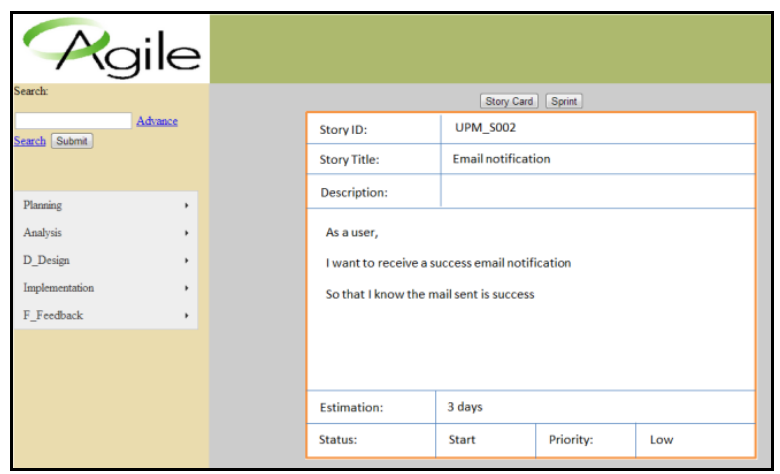

Fig. 6. EBKM system (user story details).

\section{Result ANALysis}

The aim of this paper had been achieved without the user being unaware of the underlying ontology approaches embedded in the system. The questionnaires were created based on the problem solution we want to archive. The 
ontology was evaluated based on all related practices are inserted and the relationship between them are what they used in the development environment.

In Fig. 7 shows $80 \%$ of the respondent agreed that EBKM ontology consists of all the practices used in ASD.

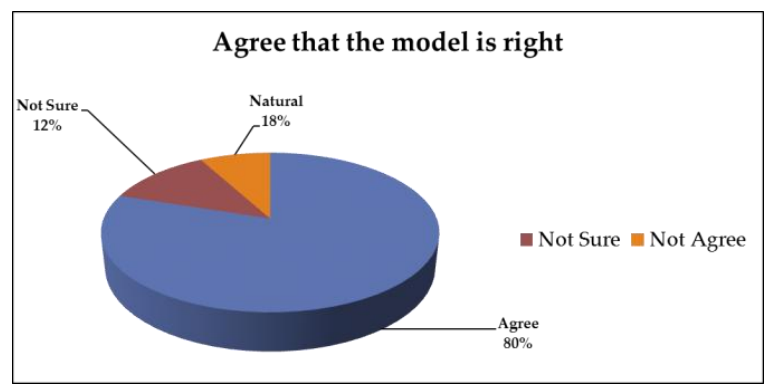

Fig. 7. Element in EBKM ontology model are related to ASD.

Next evaluation was either this model can be used to them as a reference while developing a system. Fig. 8 shows that $80 \%$ agreed that this model can be used as reference for them to start development using agile. This been evaluated based on prototype that was developed which is based on saving time ( $84 \%$ agree) and reduced development cost ( $84 \%$ agree). This result is illustrated in the Fig. 9 and Fig. 10.

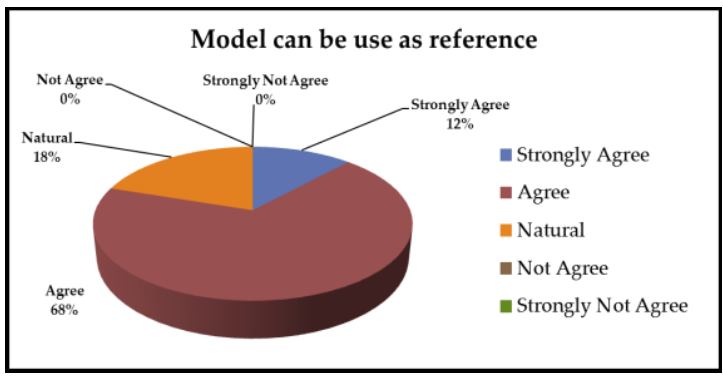

Fig. 8. EBKM use as reference.

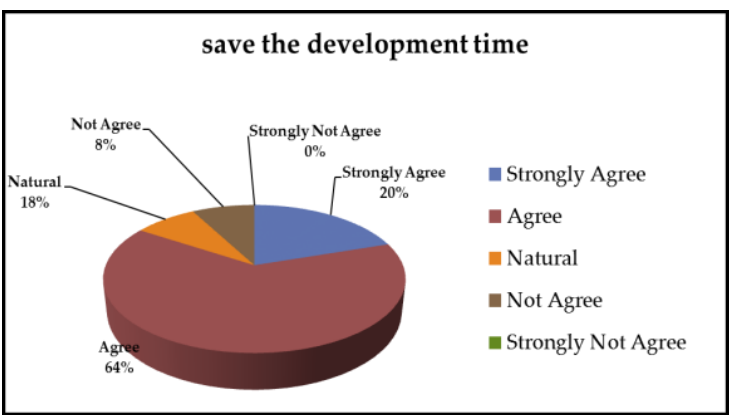

Fig. 9. Ontology help in save development time.

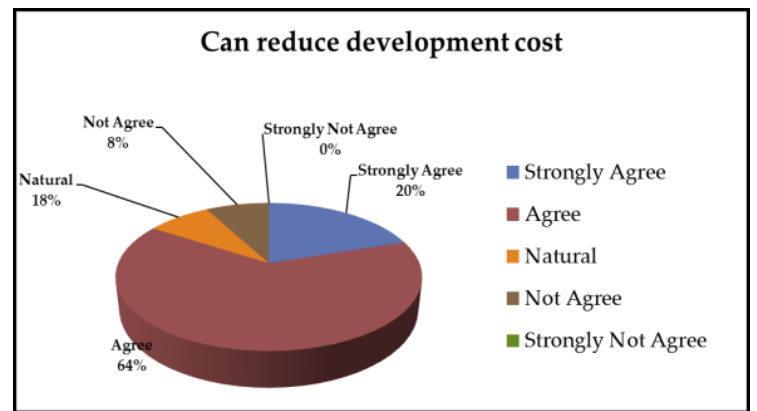

Fig. 10. Ontology help in reduce development cost.

Nevertheless, the prototype proved that the model helps CoP to share knowledge among them more easily. Most of the respondent agreed all the required data that need to be shared are displayed in the prototype which was about $82 \%$.

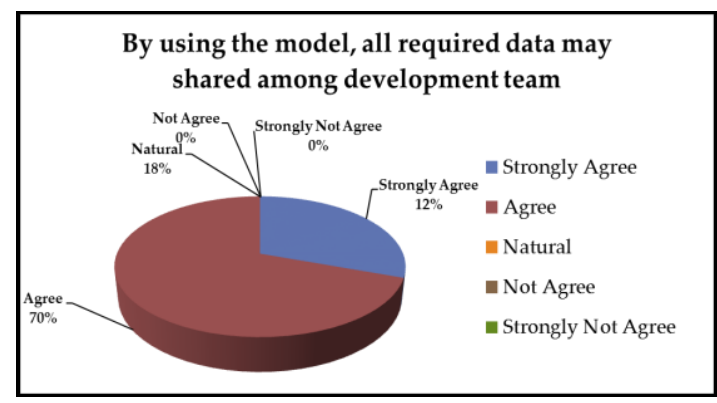

Fig. 11. Ontology help in sharing the knowledge.

\section{CONCLUSION AND FUTURE WORK}

ASD is more focus on communication and discussion rather than documentation. The issue that always been discuss by $\mathrm{CoP}$ is how they want to capture the experience knowledge that gain by the developer. Since then, lots of proposed solutions have been introduced to capture the data. The other related issue concern by $\mathrm{CoP}$ is how to easily share the collected data that been stored in repository easily among software developers to save time for development and also to reduce cost of the development.

We proposed EBKM ontology model which later on can be used to develop a web. We develop a prototype as overviews to a user how the web works based to the ontology model proposed. As the result, $84 \%$ of the respondent agreed that this proposed model help them in saving time for software development and also reduce for cost in developing the system.

In conclusion, this proposed model is useful for the CoP to refer to for them to share knowledge that will save time and reduce cost of development. There are many improvements that can be made through future work which could consider agile software development ontology evolution. For future work, we hope that a framework on how to develop a full EBKM system can be done. So that everyone can refer to the framework to create a web to share the knowledge among CoP.

\section{REFERENCES}

[1] R. Abdullah, N. S. N. A. Aziz, and M. Lakulu, "Towards Developing Lesson Learnt and Experience-Based Factory Model in Agile Software Development," Special Issue-Agile Symposium, Malaysia, Sci.Int.(Lahore), pp. 1081-84, 2013.

[2] S. S. Baboo and P. S. Priya, "Information Retrieval Using Ontology Based Authentication for Personal Identification," presented at International Conference on Software and Computer Applications (ICSCA 2012), 2012.

[3] SDLC Agile Model. [Online]. Available: http://www.tutorialspoint.com/sdlc/sdlc_agile_model.htm

[4] S. Sharma, D. Sarkar, and D. Gupta, "Agile Process and Methodologies: A Conceptual Study," International Journal on Computer Science and Engineering (IJCSE), vol. 4, no, 5, 2012.

[5] J. Highsmith and A. Cockburn, "Agile Software Development: The Business of Innovation," Computer, vol. 34, no. 9, pp. 120-122, 2001

[6] 2008 3rd Annual Survey: The State of Agile Development. [Online]. Available:

www.versionone.com/pdf/3rdAnnualStateOfAgile_FullDataReport.pd f.

[7] 2007 Agile development: Result Delivered. [Online]. Available: http://www.versionone.net/pdf/AgileDevelopment_ResultsDelivered. pdf

[8] 2009 4th Annual Survey. (2009). [Online]. Available: www.versionone.com/agilesurvey

[9] K. Beck, Extreme programming explained: embrace change, Boston, MA, USA: Addison-Wesley Longman Publishing Co., Inc., 1999. 
[10] K. Schwaber and J. Sutherland. (2011). The Scrum Guide. [Online]. Available:

www.scrum.org/storage/scrumguides/Scrum\%20Guide\%20-\%202011 .pdf

[11] G. Smith, O. Survey, D. Blackman, and B. Good, "Knowledge Sharing and Organizational Learning: The Impact of Social Architecture at Ordnance Survey," Journal of Knowledge Management Practice, 2003.

[12] A. M. Talib, R. Atan, R. Abdullah, and M. A. A. Murad, "Towards New Data Access Control Technique Based on Multi Agent System Architecture for Cloud Computing," Springer Series: Communications in Computer and Information Science, 2011.

[13] M. Lakulu, R. Abdullah, M. H. Selamat, H. Ibrahim, and M. Z. M. N. M. Nor, "A Framework of Collaborative Knowledge Management System in Open Source Software Development Environment," Computer and Information Science, vol. 3, no. 1, p. 81, 2010.

[14] M. Levy and O. Hazzan, "Knowledge Management in Practice: The case of Agile Software Development," ICSE2009, IEEE, 2009.

[15] D. Bennet, and A. Bennet, "The Rise of the Knowledge Organisation," in C. W. Holsapple, (ed.), Handbook on Knowledge Management, vol. 1, Springer, Berlin, pp. 5-20, 2003.

[16] D. J. Reifer, "How to Get the Most out of Extreme Programming/Agile Methods," in Proc. Extreme Programming and Agile Methods XP/Agile Universe, 2002.

[17] B. Boehm and R. Turner, Balancing Agility and Discipline, Addison-Wesley, 2004.

[18] R. Dove, "Knowledge management, response ability, and the agile enterprise," Journal of Knowledge Management, vol. 3, issue 1, pp. $18-35,1999$.

[19] H. Holz, G. Melnik, and M. Schaaf, "Knowledge Management for Distributed Agile Processes: Models, Techniques, and Infrastructure," WETICE, pp 291-294, 2003.

[20] A. Singh, K. Singh, N. Sharma, "Managing Knowledge in Agile Software Development," presented at International Conference on Recent Advances and Future Trends in Information Technology(iRAFIT2012), 2012.

[21] H. Hedberg and J. Iisakka, "Technical Reviews in Agile Development: Case Mobile-D," presented at IEEE Sixth International Conference on Quality Software, 2006.

[22] R. K. Kavitha and M. S. I. Ahmed, "A Knowledge Framework for Agile Software Development Teams," IEEE 2011 International Conference on Process Automation, Control and Computing (PACC), 2011.

[23] G. Klyne and J. J. Carroll. (2004). Resource Description Framework (RDF): Concepts and Abstract Syntax. [Online]. Available: http://www.w3.org/TR/rdf-concepts/.

[24] D. L. McGuinness and F. V. Harmelen. (2004). OWL Web Ontology Language Overview. [Online]. Available: http://www.w3.org/TR/owl-features/. ]

[25] T. Finin et al., "Automatically Generated DAML Markup for Semistructured Documents," in Proc. 2003 AAAI Spring Symposium on Agent-Mediated Knowledge Management (AMKM), 2003.

[26] D. Fensel et al., "OIL: An Ontology Infrastructure for the Semantic Web. IEEE Intelligent Systems," MARCH/APRIL, 2001.

[27] I. Horrocks and F. V. Harmelen, Reference Description of the DAML+OIL Ontology Markup Language, 2001

[28] S. Luke and J. Heflin, "SHOE 1.01 Proposed specifications," Shoe Project, 2000.

[29] P. Wongthongtham, E. Chang, T. Dillon, and I. Sommerville, "Development of a Software Engineering Ontology for Multi-site
Software Development," IEEE Transactions on Knowledge and Data Engineering, 2009

[30] H. Knublauch, "Ramblings on Agile Methodologies and Ontology-Driven Software Development,"Workshop on Semantic Web Enabled Software Engineering, Galway, Ireland, 2005.

[31] D. Parsons, "Agile Software Development methodology," Academia.edu share research, Auckland, New Zealand, 2009.

[32] K. M. Shenoy, K. C. Shet, and U. D. Acharya, "Interoperability using Ontology Mapping," Journal of Computer Science and Engineering, vol. 5, Jan 2011.

[33] A. R. Basariya, O. S. J. Nisha, "Semantic Based Query Optimization using Ontology for Knowledge Management," IEEE - International Conference on Advances in Engineering, Science and Management (ICAESM), 2012.

[34] M. R. Genesereth. (1998). Knowledge Interchange Format - draft proposed American National Standard. [Online]. Available: http://logic.stanford.edu/kif/dpans.html

[35] R. J. Brachman and J. G. Schmolze, "An overview of the KL-ONE knowledge representation system," Cognitive Science, pp. 171-216, 1985.

[36] A. Farquhar, R. Fikes, and J. Rice, "The Ontolingua Server: A Tool for Collaborative Ontology Construction," 10th Knowledge Acquisition for Knowledge-Based Systems Workshop. Banff, Canada, 1996.

[37] R. MacGregor, "Inside the LOOM description classifier," SIGART bulletin, vol. 2, no. 3, pp. 70-76, 1991.

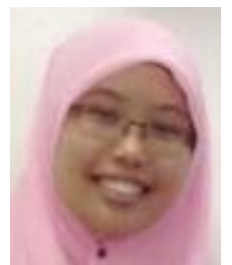

Nik Sakinah Nik Ab Aziz was born in Terengganu, Malaysia on 1986. She received the B.S degree in computer science from the Universiti Teknikal Malaysia Melaka (UTeM), Malaysia in 2009.

She has four years experiences of system development as a System Analyst from one of the software house in Selangor. Her profession focus covers the area of software development cycle in developing a system. Currently, she is working towards the M.S Degree in Software Engineering from Universiti Putra Malaysia (UPM), Malaysia. Her project and research interest include studying the knowledge management and agile software development.

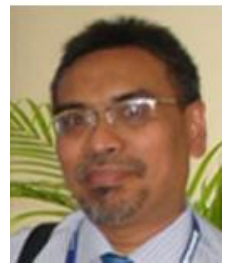

Rusli Abdullah is an associate professor in Information System Department, Faculty of Computer Science and Information Technology, of Universiti Putra Malaysia. He holds a B.Sc in computer science from Universiti Putra Malaysia in 1988, M.Sc in computer science from Universiti Putra Malaysia in 1996, and PhD in knowledge management at Faculty of Computer Science and Information System at Universiti Teknologi Malaysia in 2005.

$\mathrm{He}$ has more than 12 years of teaching experience and about 8 years of system development experience as a system analyst at higher learning institutions. He currently teaches System Analysis and Design, and Software Quality at both undergraduate and graduate levels. His research interests include knowledge management and software engineering, computer supported collaborative of work, and workflow management

He has also published and written books, articles, and technical papers in numerous journals and conference proceedings with regards to his research interests. Some of his published books in Malay version are Introduction to Workgroup Computing, Introduction to Analysi s and Design Systems, and Information Technology and Its Applications. 